\title{
Keep it simple: Repair of atrioventricular valve regurgitation in patients with a single ventricle
}

\author{
Jennifer C. Romano, MD, MS
}

From the Section of Congenital Heart Surgery, Departments of Cardiac Surgery and Pediatrics, Michigan Medicine, University of Michigan, Ann Arbor, Mich.

Disclosures: Author has nothing to disclose with regard to commercial support.

Received for publication Oct 17, 2017; accepted for publication Oct 27, 2017; available ahead of print Dec 7, 2017.

Address for reprints: Jennifer C. Romano, MD, MS, Departments of Cardiac Surgery and Pediatrics, 11-733 C. S. Mott Children's Hospital, SPC 4204, 1540 E Hospital Dr, Ann Arbor, MI 48109-4204 (E-mail: jhirsch@umich. edu).

J Thorac Cardiovasc Surg 2018;155:710-1

$0022-5223 / \$ 36.00$

Copyright (c) 2017 by The American Association for Thoracic Surgery

https://doi.org/10.1016/j.jtcvs.2017.10.105

Ono and colleagues ${ }^{1}$ present an impressive compilation of patients with a single ventricle who have required intervention for atrioventricular (AVV) regurgitation. The study encompasses an impressive number of patients, but is most notable for an extensive cataloging of valve anomalies and repair techniques. The group should be applauded for diligent reporting and excellent outcomes in this challenging patient cohort. Despite a reintervention rate of $24 \%$, they still report an impressive $88 \%$ survival following the Fontan procedure in those undergoing AVV repair. These outcomes are certainly in line with those of large centers of excellence internationally. The study presents a belief held by most congenital heart surgeons: if you are a single-ventricle patient, AVV regurgitation is bad. It portends an increased need for reintervention on the AVV and a decrease in late survival compared with those without AVV regurgitation. Despite the impressive list of details and categorizations, Ono and colleagues ${ }^{1}$ leave one wanting an answer to the question: What is the best way to approach these valves?

At the University of Michigan, the approach for AVV regurgitation in patients with hypoplastic left heart syndrome has focused on posterior leaflet obliteration. ${ }^{2,3}$ Numerous studies have clearly shown that cardiopulmonary bypass and, specifically, aortic crossclamp times, are deleterious for patients with a single ventricle, especially at the time of Fontan. ${ }^{4} \mathrm{We}$ have an institutional bias to forego extensive evaluations of the valve anomalies and vagaries we know these patients are at risk of experiencing, and go straight to a simple and quick posterior leaflet obliteration. Through this approach, a high rate of immediate and late success has been achieved with significantly shortened cardiopulmonary bypass and crossclamp times-both of which are well known to contribute to right ventricle dysfunction and late mortality. Although this technique is limited to tricuspid AVV, the principle remains. In a patient with a single ventricle,

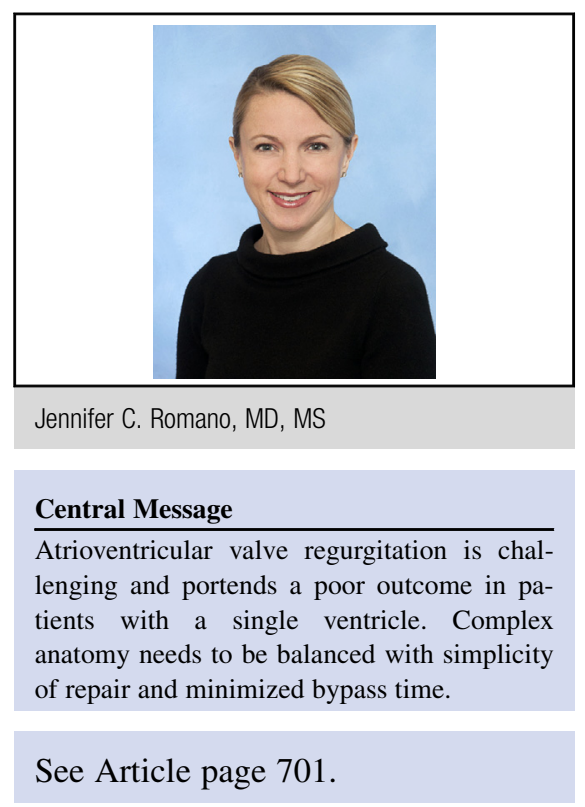

prolonged and complicated valve repair technical successes may be limited by complexity and the associated bypass times. Simpler repairs based on annular reduction and reducing prolapse may provide improved outcomes by limiting myocardial ischemia in patients with a single ventricle.

It is clear that AVV regurgitation, most commonly occurring in common AVV and tricuspid valves, is a daunting challenge for continued staged palliation. Those who fail AVV repair are often those with associated ventricular dysfunction that ultimately dominates and results in recurrent AVV failure. With an impressive array of details of anatomic valvular pathology and a myriad of repair techniques, Ono and colleagues, ${ }^{1}$ findings are supportive of the challenge. If you need intervention on your AVV, there is a higher risk of reintervention and late mortality. ${ }^{1}$ Unknown is the most successful and durable repair option or how to predict those at greatest risk. In the absence of this knowledge, employing the technique that is quick, simple, and associated with a high rate of success seems to make sense to minimize the prolonged bypass times that are known to be harmful for this challenging and growing population.

\section{References}

1. Ono M, Cleuziou J, Pabst von Ohain J, Beran E, Burri M, Strbad M, et al. Atrioventricular valve regurgitation in patients undergoing total cavopulmonary 
connection: impact of valve morphology and underlying mechanisms on survival and reintervention. J Thorac Cardiovasc Surg. 2018;155:701-9.e6.

2. Ohye RG, Gomez CA, Goldberg CS, Graves HL, Devaney EJ, Bove EL. Tricuspid valve repair in hypoplastic left heart syndrome. J Thorac Cardiovasc Surg. 2004; 127:465-72.
3. Dinh DC, Gurney JG, Donohue JE, Bove EL, Hirsch JC, Devaney EJ, et al. Tricuspid valve repair in hypoplastic left heart syndrome. Pediatr Cardiol. 2011;32:599-606.

4. Hirsch JC, Goldberg C, Bove EL, Salehian S, Lee T, Ohye RG, et al. Fontan operation in the current era: a 15-year single institution experience. Ann Surg. 2008;248:402-10. 